CONF-8710111--32

DE88 005956

\title{
EFFECT OF DECONTAMINATION ON AGING PROCESSES AND CONSIDERATIONS FOR LIFE EXTENSION*
}

\author{
D. R. Diercks \\ Materials and Components Technology Division \\ Argonne National Laboratory \\ Argonne, IL 60439
}

\section{October 1987}

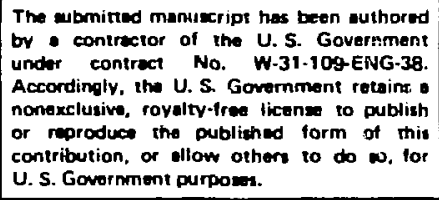

\section{DISCLAIMER}

This report was prepared as an account of work sponsored by an agency of the United States Government. Neither the United States Government nor any agercy thereof, nur any of their employees, makes any warranty, express or implied, or assumes any legal liability or responsibility for the accuracy, completeness, or usefulness of any information, apparatus, product, or process disclosed, or represents that its use would not infringe privately uwned rights. Reference herein to any specific commercial product, process, or service by trade name, trademark, manufacturer, or otherwise does not necessarily constitute or imply its endorsement, recommendation, or favoring by the United States Governnient or any agency thereol I he biews

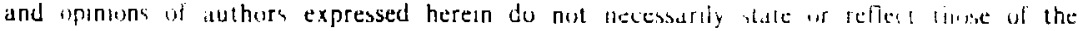
United Sittes Guvernment or any agtency thereof

To be pres:ented at the Fifteenth Water Reactor Safety hnformation Meeting, National Bureau of Standards, Gaithersburg, MD, October 26-30, 1987.

Work Supported by the U. S. Nuclear Regulatory Commission, Office of Nuclear Regulatory Research, USNRC. FIN No.: A2259. Program Mianager: F. Cardile.

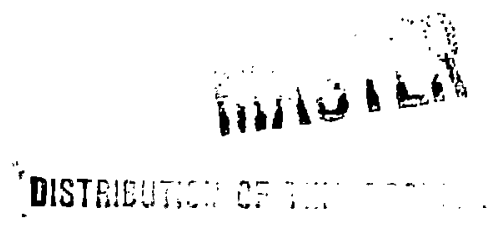




\title{
EFFECT OF DECONTAMINATION ON AGING PROCESSES
} AND CONSIDERATIONS FOR LIFE EXTENSION

\author{
D. R. Diercks \\ Materials and Components Technology Division \\ Argonne National Laboratory \\ Argonne, IL 60544
}

\begin{abstract}
The basis for a recently initiated program on the chemical decontamination of nuclear reactor components and the possible impact of decontamination on extended-life service is described. The incentives for extending plant life beyond the present 40-year limit are discussed. and the possible aging degradation processes that may be accentuated in extended-life service are described. Chemical decontamination processes for nuclear plant primary systems are summarized with respect to their corrosive effects on structural alloys, partieularly those in the aged condition. Available experience with chemical cleaning processes for the secondary side of PWR steam generators is also briefly considered. Overall, no severe materials corrosion problems have been found that would preclude the use of these chemical processes, but concerns have been raised in several areas, particularly with respect to corrosion-related problems that may develop during extended service.
\end{abstract}

\section{INTRODUCTION}

This paper describes the basis for a recently initiated program on the decontamination of nuclear reactor components and the possible impact of decontamination on extended-life service. This program is being developed in response to the ever-increasing use of chemical decontamination processes in nuclear power plants to reduce worker exposures during repairs and maintenance, and to a growing interest in extending the life of existing nuclear plants beyond their present 40-year licensing period. Concerns about the possible adverse effects of repeated decontaminations on the remaining service life of aged components must be addressed before operating licenses for extended life can be renewed. Although a wide variety of nuclear power plant components are subject to aging effects of one kind or another, the present program is specifically concerned with metallurgical and chemical effects in components that are directly exposed to decontamination solutions, i.e., selected pressure boundary components and reactor internals. In addition. chemical cleaning of steam generators to remove sludge and reduce denting, though not strictly a decontamination process, is also included. 


\section{PLANT LIFE EXTENSION AND COMPONENT AGING}

The duration of a license for a nuclear power plant was set at a maximum of 40 years by the Atomic Energy Act of 1954, with possible renewal at the end of that time period. ${ }^{1}$ Several studies ${ }^{2-4}$ to evaluate the technical and economic merits of extending service lives beyond this 40-year limit have found that such life extensions are technically feasible and that the economic incentives are considerable. A 1982 evaluation performed for the Electric Power Research Institute (EPRI) concluded that such life extension could be cost-effective even at a plant refurbishment cost of $\$ 300$ million to $\$ 1$ billion. ${ }^{3}$ Robert B. Minogue, former Director of the Office of Nuclear Research of the U. S. Nuclear Regulatory Commission (USNRC), has noted that present 40-year operating licenses for nuclear power plants will begin to expire in the year 2001, and by 2015 approximately 85 percent of the licenses granted through 1985 will have expired. ${ }^{5}$ It is therefore not surprising that the USNRC has aiready begun to seriously examine the safety implications associated with nuclear power plant life extension. ${ }^{6}$

The major concern with respect to the possible licensing of nuclear plants for operation beyond 40 years is that of component aging. In terms of metallurgical effects, such aging can take several forms, including low-temperature sensitization of stainless steels, long-term embrittlement of cast duplex stainless steels, and radiation-induced embrittlement of reactor internal components. Each of these aging phenomena will be discussed briefly.

It has been recognized only relatively recently that sensitization of stainless steels can occur after prolonged exposures (of the order of years) to temperatures of $400^{\circ} \mathrm{C}\left(750^{\circ} \mathrm{F}\right)$ or less.7.8 This process, known as low-temperature sensitization, generally requires an initial brief exposure to higher temperatures $\left(600\right.$ to $800^{\circ} \mathrm{C}$ or 1110 to $\left.1470^{\circ} \mathrm{F}\right)$ to nucleate the carbide particles that subsequently grow at lower temperatures. Just as with conventional sensitization, this precipitation process depletes the grain-boundary regions of $\mathrm{Cr}$ and leaves them more susceptible to intergranular corrosion. Low-temperature sensitization is of concern in nuclear plant coolant piping and reactor internals operating at temperatures of 250 to $288^{\circ} \mathrm{C}\left(480\right.$ to $550^{\circ} \mathrm{F}$ ), particularly under conditions of extended-life operation.

Another aging phenomenon, sometimes known as $475^{\circ} \mathrm{C}$ embrittlement, can occur in ferritic and cast duplex stainless stainless steels. When these steels are exposed for extended periods of time to temperatures in the range from 300 to $500^{\circ} \mathrm{C}$, the $\mathrm{Cr}$-rich $\alpha^{\prime}$ phase precipitates within the ferrite, resulting in severe embrittlement. It now appears that a similar series of time-dependent precipitation phenomena may occur at LWR operating temperatures in the ferrite phase of cast duplex stainless steels such as CF-3 and $\mathrm{CF}-8$, which are used to fabricate nuclear plant primary coolant piping as well as valve and pump casings. 9 Again, these very slow aging processes are of greacest concern under conditions of extended-life operation. 
The embrittlement of reactor pressure vessels and internal components due to neutron irradiation may also be considered to be an aging phenomenon of sorts. This embrittlement process is generally characterized in terms of an increase in the transition temperature between brittle behavior observed at lower temperatures and ductile fracture at higher temperatures. This transition temperature increases with increasing neutron fluence (and therefore service time), and it has also been found to be strongly influenced by the presence of certain impurities such as $\mathrm{Cu}$ and $\mathrm{Ni}$ in the steel. Control of these residual element levels has greatly reduced the embrittlement problem in the newer reactor pressure vessels, but older vessels will require careful moıtitoring, particularly if extended-life operations are attempted.

\section{CHEMICAL DECONTAMINATION}

During the operation of a nuclear power plant (BWR or PWR), oxide corrosion films form on the surfaces of piping, pumps, valves, steam generator tubing, and other components in contact with the primary coolant. Some of these corrosion products dissolve or erode in the circulating coolant, are deposited on the fuel cladding, and become activated. The principal radionuclides formed by this activation process are ${ }^{58} \mathrm{Co},{ }^{60} \mathrm{Co},{ }^{55} \mathrm{Fe},{ }^{59} \mathrm{Fe}$, ${ }^{54} \mathrm{Mn},{ }^{51} \mathrm{Cr},{ }^{63} \mathrm{Ni}$, and ${ }^{65} \mathrm{Zn}$. These radionuclides, in turn, are released and carried out of the core region by the coolant and are incorporated into the oxide films on the surfaces of the primary coolant system components. The result is a steadily increasing radiation field on these components.

This radiation field is of principal concern during reactor outages for maintenance or repair. since it limits the working time of personnel in the region. In fact, radiation exposure represents a specific cost, commonly quoted as $\$ 5000$ to $\$ 7000$ per man-rem, ${ }^{10,11}$ that electrical utilities must bear during maintenance and repair procedures. Decontamination of primary loop components to reduce radiation fields and lower the man-rem exposure is therefore of vital economic interest to utilities. For example, based upon experiences with the Dresden 3 and Quad Cities 1 and 2 reactors, Commonwealth Edison Company reports average net savings of $\$ 1.25$-million from decontamination of recirculation piping preparatory to performing in-service inspection and repair work. 12 Reduction of the radiation exposure of nuclear plant personnel through effective decontamination is also consistent with the NRC objective of maintaining such exposure as low as reasonably achievable (ALARA).

The results of a survey of U. S. experience with the chemical decontamination of commercial nuclear power reactors are summarized in Table I. This tabulation is not necessarily exhaustive, but it does include a large majority of the chemical decontaminations that were performed in this country through the end of 1986. Most of the decontaminations were carried out on BWR primary coolant recirculation systems (PCRS) and reactor water clean-up systems (RWCU). In PWRs, the components most commonly decon ${ }^{-1}$ minated have been steam generator channel heads. Almost all of these iccontaminations were carried out immediately prior to maintenance 
Table I. Summary of Experience with Chemical Decontamination of Commercial Nuclear Power Reactors in the United States.

\begin{tabular}{|c|c|c|c|c|}
\hline Date & Plant & Process & $\begin{array}{c}\text { Components } \\
\text { Decontaminated }\end{array}$ & $\begin{array}{l}\text { Years Since } \\
\text { Startup }\end{array}$ \\
\hline \multicolumn{5}{|c|}{ Boiling Water Reactors } \\
\hline 1964 & Shippingport & Turco $4502 / 4521$ & PCRS & 7 \\
\hline $6 / 76$ & Dresden 1 & NS-1 (conc.) & Primary system test loop & 16 \\
\hline $4 / 77$ & Peach Bottom 3 & NS-1 (conc.) & RWCS & 3 \\
\hline $9 / 77$ & Peach Bottom 2 & NS-1 (conc.) & RWCS & 3 \\
\hline $10 / 79$ & Vermont Yankee & CAN-DECON & RWCS & 7 \\
\hline $3 / 80$ & Brunswick 2 & CAN-DECON & RWCS & 4 \\
\hline $3 / 81$ & Nine Mile Point & CAN-DECON & 5 primary recirc. pumps & 4 \\
\hline $4 / 81$ & Brunswick 1 & CAN-DECON & RWCS & 4 \\
\hline $10 / 81$ & Vermont Yankee & CAN-DECON & RWCS & 9 \\
\hline $12 / 31$ & Brunswick 1 & CAN-DECON & aux. steam system & 5 \\
\hline $4 / 82$ & Peach Bottom 2 & CAN-DECON & RWCS & 8 \\
\hline $4 / 82$ & Nine Mile Point & CAN-DECON & 2 primary recirc. pumps & 12 \\
\hline $5-8 / 82$ & Nine Mile Point & CAN-DECON & PCRS & 12 \\
\hline $12 / 82$ & Hatch 1 & CAN-DECON & RWCS & 7 \\
\hline $4 / 83$ & Peach Bottom 3 & CAN-DECON & RWCS & 8 \\
\hline $3-4 / 83$ & Vermont Yankee & CAN-DECON & PCRS & 10 \\
\hline $10 / 83$ & Quad Cities 2 & CAN-DECON & PCRS & 11 \\
\hline $10 / 83$ & Dresden 3 & CAN-DECON & PCRS and RWCS & 12 \\
\hline $1 / 84$ & Pilgrim & NS-1 (dilute) & PCRS & 11 \\
\hline $3 / 84$ & Monticello & LOMT & PCRS and RWCS & 13 \\
\hline $4 / 84$ & Quad Cities 1 & CAN-DECON & RWCS & 12 \\
\hline $4 / 84$ & Brunswick 2 & Citrox & RWCS & 8 \\
\hline $5 / 84$ & Millstone 1 & CAN-DECON & PCRS and RWCS & 14 \\
\hline $7 / 84$ & Peach Bottom 2 & CAN-DECON & PCRS & 10 \\
\hline $7-3 / 84$ & Pilgrim & NS-1 (dilute) & PCRS and RWCS & 12 \\
\hline
\end{tabular}


Table I. (Cont'd.)

\begin{tabular}{llccc}
\hline Date & Plant & Process & $\begin{array}{c}\text { Components } \\
\text { Decontaminated }\end{array}$ & $\begin{array}{c}\text { Years Since } \\
\text { Startup }\end{array}$ \\
\hline $9 / 84$ & Dresden 1 & NS-1 (conc.) & PCRS & 24 \\
$10 / 84$ & Dresden 2 & NS-1 (dilute) & PCRS & 14 \\
$12 / 84$ & Cooper & Citrox (dilute) & PCRS & 10 \\
1984 & Quad Cities 2 & CAN-DECCN & RWCS & 12 \\
$10 / 85$ & Vermont Yankee & LOMI & PCRS and RWCS & 13 \\
$11 / 85$ & Dresden 3 & LOMI & PCRS and RWCS & 14 \\
$1 / 86$ & Quad Cities 2 & LOMI & PCRS & 13 \\
$5 / 86$ & Quad Cities 1 & CAN-DECON/LOMI & 2 irrad. fuel assemblies & 14 \\
$6 / 86$ & Oyster Creek & LOMI & PCRS & 17 \\
$7 / 86$ & Brown's Ferry 1,2,\&3 & 7 processes & 6 RWCS pumps & $9-12$ \\
& & compared & LCRS and RWCS (hot leg) & 16
\end{tabular}

\section{Pressurized Water Reactors}

\begin{tabular}{ll}
1976 & Surry \\
$9 / 82$ & Surry 2 \\
$11 / 82$ & Surry 2 \\
$4 / 83$ & Ginna \\
$8 / 83$ & Millstone 2 \\
$8 / 84$ & Palisades \\
$5 / 85$ & Millstone 2 \\
1985 & Indian Point 3 \\
$1 / 86$ & Connecticut Yankee \\
$6-8 / 86$ & H. B. Robinson \\
1986 & Millstone 2 \\
\hline
\end{tabular}

NS-1 (conc.)
CAN-DECON
LOMI
CAN-DECON
OZOX
CAN-DECON
CitroX A
LOMI
CAN-DECON
LOMI
OZOX-A

Evaporacor

Channel head (cold leg) $\quad 9$

Channel head (hot leg) $\quad 9$

Channel heads $\quad 13$

Chännel heads 8

Channel heads $\quad 13$

Channel heads $\quad 10$

Channel heads 9

Channel heads $\quad 18$

Isolated primary pump $\quad 15$

Channel heads $\quad 11$

* PCRS = Primary Coolant Recirculation System RWCS = Reactor Water Cleanup System 
or repair work to reduce worker exposure. The principal decontamination processes were CAN-DECON, NS-1, and, in more recent years, LOMI. It is apparent from the table that chemical decontamination is becoming an increasingly common practice in this country.

During a nuclear reactor decontamination, the chemical solutions are likely to come in contact with a number of different structural alloys. The more important alloys are listed in Table II along with examples of components in which they are utilized. Although core decontaminations with the fuel in place are not yet being routinely performed in this country, they have been performed in Canada (Douglas Point and Pickering Candu Reactors) and the U. K. (Winfrith SGHWR), and are of growing interest in the U. S. For this reason, Zircaloy cladding material is included in Table II. The high-strength Ni-base Inconel Alloys 718,625, and X-750, which are used for core structural applications, are included for the same reason.

It should be noted that several of the alloys listed in Table II are susceptible to the longi-term metallurgical aging effects previously described. For example, the austenitic stainless steels (SS) and, to a lesser extent, Incoloy $600 \mathrm{C}$ are subject to low-temperature sensitization, although Type 316 NG SS has been specifically developed to resist sensitization. Possible aging embrittlement of the cast duplex stainless steels CF-8 and CF-3 has already been discussed, as has the neutron irradiation embrittlement of the carbon steel pressure-vessel materials.

\section{CORROSIVE EFFECTS OF DECONTAMINATION PROCESSES}

Table I indicates that the most widely used decontamination processes in this country are CAN-DECON and, more recently, LOMI, and these two processes are of principal interest in the present program. Both processes have been extensively studied for possible corrosive effects on the reactor structural materials with which they come in contact during use. The results of these studies are summarized in this paper.

\section{CAN-DECON Process}

The CAN-DECON process is a dilute chemical decontamination process developed by Atomic Energy of Canada Ltd. (AECL) during the early 1970's. 13 The process was first used on a commercial basis in the United States to decontaminate the RWCS of the Vermont Yankee BWR in late 1979. Since that time, more than 20 decontaminations of BWR's and PWR's have been carried out in this country with CAN-DECON.

The principal active chemical reagent used in the CAN-DECON process was originally INutek L-106, sold by Nuclear Technology Corp. of Amston, CN. 14 Since 1977, when London Nuclear Decontamination Ltd. (now LN Technologies) became the licensee of the AECL for the application of the process, the chemically similar reagent LND-101A has been utilized. This reagent consists of a mixture of organic acids (including oxalic acid) to 
Table II. Nuclear Reactor Structural Alloys Likely to be Exposed to Decontaminant Solutions During Chemical Decontamination.

\section{Alloy}

Application

Austenitic Stainless Steels

Type 304

Type 316 NG

Types 308 and 309

Cast Duplex Stainless Steels

CF-8

CF-3

Carbon and Low-alloy Steels

A.106

SA333, Grade B

A516, Grade 70

A508, Grade 2

A533, Grade B

A302, Grade B

A570, Grade 40

Nickel-base Alloys

Inconel 600

Inconel 718

Inconel 625

Inconel X-750

Special Purpose Alloys

Zircaloy-2 and -4

Haynes Stellite 6B

Haynes Stellite 6
Primary coolant piping

Primary coolant piping Corrosion-resistant cladding on pressure vessels and piping

Primary coolant piping; valve and pump casings

Primary coclant piping Primary coolant piping Primary coolant piping Reactor pressure vessel Reactor pressure vessel Steam generator shells Steam generator support plates

PWR steam generator tubing

Core structural components

Core structural components

Core structural components

Nuclear fuel cladding Control element drives Weld-deposited hard facing on pumps and valves 
dissolve the radioactive oxide films present on the components and a chelant to prevent redeposition of dissolved radioactive metal ions. The oxide films formed on PWR steam generator components typically contain more $\mathrm{Cr}$ (as much as $40 \mathrm{wt}$. \%) than is present in typical BWR corrosion films. ${ }^{15}$ Chromium is present as $\mathrm{Cr}^{3+}$ ions, which are insoluble in the LND-101A reagent and its modifications. It is therefore necessary to utilize an alkaline permanganate solution (LND-104) to oxidize the $\mathrm{Cr}^{3+}$ ions to the soluble $\mathrm{Cr}^{6+}$ state. In decontaminating PWR components, therefore, the reducing LND-101A treatments are typically preceeded by or are alternated with the oxidizing LND-104 treatments.

The CAN-DECON LND-101A solution is typically injected into the circulating reactor coolant in sufficient quantity to achieve a diluted concentration of $0.1 \mathrm{wt} . \%$ in solution. A side stream of circulating solution is passed through a fiiter and cation resin columns to remove particulate and dissolved materials. The normal decontamination temperature is $120^{\circ} \mathrm{C}$ $\left(248^{\circ} \mathrm{F}\right)$, but decontaminations have been carried out successfully at temperatures from approximately 80 to $135^{\circ} \mathrm{C}$. 16

Concerns about the possible detrimental effects of LND-101A on LWR structural alloys were first raised in early 1982 in conjunction with the decontamination of the Nine Mile Point 1 BWR primary coolant recirculation system (PCRS). 17 This decontamination was carried out in order to reduce worker exposure during repairs to safe end-to-pipe welds in the 28-in. diameter coolant lines, which developed through-wall leaks in the heat-affected zones of the welds. A Task Force formed to study the Nine Mile Point 1 failures also considered the question of whether the CAN-DECON decontamination performed immediately prior to component removal contributed to the observed cracking. The Task Force report, issued in September 1982, concluded that "...the 1982 total recirculation system decontannination does not appear to have exacerbated the observed cracking." 17 Its only clear effect, insofar as the cracking was concerned, was "...the increase in sensitivity for inspection of cracks which already existed in the system." 17 However, some of the piping welds were heavily electropolished after decontamination to further reduce radiation levels, and this electropolishing treatment removed some of the original inner surface where intergranular attack (IGA) induced by the decontamination process might have occurred. Furthermore, the failed piping was removed immediately after decontamination and therefore never saw actual reactor service. The Task Force report cautioned that longer term exposures after decontamination might reveal effects related to subsequent crack initiation. ${ }^{18}$

Laboratory tests of the CAN-DECON LND-101A reagent and studies of its possible contribution to the corrosion of reactor structural materials were conducted in 1984 by the General Electric Co. under EPRI sponsorship. ${ }^{19}$ Three LWR structural materials, namely sensitized Type 304 stainless steel, Inconel 600, and SA 533 Grade B pressure-vessel low-alloy steel, were evaluated in laboratory tests. Decontamination processing for $48 \mathrm{~h}$ at $120^{\circ} \mathrm{C}$ in a $0.1 \mathrm{wt}$. \% solution of LND-101A produced relatively high corrosion rates of about $0.18 \mathrm{~mm} /$ day in the low alloy steel, but the rates for the other two 
alloys were of the order of $10^{-3} \mathrm{~mm} /$ day. However, the decontamination process was found to have produced IGA to a depth of aboutt $0.2 \mathrm{~mm}$ ( 2 to 3 grain diameters) in the Type 304 stainless steel specimer's and $0.09 \mathrm{~mm}$ ( 3 grain diameters) in the Inconel 600 specimen. In addition, surface pitting was observed in these latter two materials. Subsequent constant extension rate tensile (CERT) tests at $288^{\circ} \mathrm{C}\left(550^{\circ} \mathrm{F}\right)$ in water containing $0.2 \mathrm{ppm}$ dissolved oxygen indicated an increased susceptibility to stress corrosion cracking (SCC) in the sensitized Type 304 stainless steel. In the case of field-decontaminated Type 304 stainless steel BWR pipe welds. shallow IGA was observed in the heat affected zone, and dense shallow oits were found in one specimen. However, neither of these features adversely affected the IGSCC resistance of these specimens as measured by CERT tests.

As a follow-up to the General Electric study, London Nuclear conducted a comprehensive review of general, galvanic, crevice, and pitting corrosion data and SCC test results for the CAN-DECON process obtained by them and others over a number of years. $16,20-23$ The alloys evaluated included several carbon steels, austenitic and ferritic stainless steels, nickel-base alloys. Zircaloy-2, and Stellite 6 . The LND-101A reagent concentrations in these tests ranged from 0.05 to $0.3 \mathrm{wt}$ \%; solution temperatures ranged from 25 to $135^{\circ} \mathrm{C}$; and decontamination times ranged from 6 to $550 \mathrm{~h}$. This study concluded that the LND-101A solution does not, in general, produce any undesirable corrosion effects in the evaluated alloys. The highest corrosion rates were observed in the carbon steels, with a maximum rate of about $0.19 \mathrm{~mm} /$ day. However, this rate could be reduced by about a factor of $10 \mathrm{by}$ the addition of suitable corrosion inhibitors. Non-sensitized Type 304 stainless steel and Inconel 600 showed no increase susceptibility to IGSCC. In the sensitized conditions, these two alloys showed a significant susceptibility to IGSCC after a 500-h treatment when the solution contained no ferric ions. The addition of ferric ions at concentrations of $\sim 50$ to $80 \mathrm{ppm}$ in the decontaminant solution eliminated the susceptibility to IGA and IGSCC. The enhanced IGA and IGSCC susceptibility previously observed in the General Electric studies was therefore attributed to a lack of ferric ions in solution, a condition that would not normally be present during actual reactor decontamination, except possibly for a brief period near the beginning of the decontamination process. For this reason London Nuclear has introduced a reformulated version of LND-101A, known as Rem-E-D, which contains ferric citrate additions to ensure a sufficiently high concentration of ferric ions during the initial stages of decontamination. In addition, London Nuclear concluded that the presence of oxalic acid in the LND-101A reagent can lead to IGA of certain alloys under severe conditions. Therefore, reagent LND-107, in which the oxalic acid has been removed, was also introduced as an alternative modification of the original LND-101A. ${ }^{13}$

\section{LOMI Process}

The LOMI (low oxidation.state metal ion) decontamination process ${ }^{24}$ was developed by the Central Felectricity Generating Board in Great Britain. and is rurrently licensed to several firms for use in the United States. The deconiaminating reagent consists of low concentrations of picolinic acid and 
vanadium (II) formate plus a chelating agent, and the process works by converting the ferric ions in the oxide layer on the contaminated component surfaces to the more soluble ferrous ions, with the $\mathrm{V}^{2+}$ jons serving as the reductant. For PWR oxide films, which typically have a higher $\mathrm{Cr}$ concentration, prior alkaline or nitric acid permanganate (AP or NP) oxidation treatments are commonly used. 'The LOMI reagent is injected into the circulating reactor coolant as with the CAN-DECON process, and a side stream of circulating coolant plus decontamination solution is again passed through a filter and cation exchange resing columns to regenerate the chelant. The normal decontamination temperature of 80 to $90^{\circ} \mathrm{C}(176$ to $194^{\circ} \mathrm{F}$ ) for the LOMI process is somewhat lower than the decontamination temperature for the CAN-DECON process.

Both General Electric Company 19 and Pacific Northwest Laboratories $(\mathrm{PNL})^{25}$ have conducted studies on the corrosive effects of the LOMI process on LWK structural materials. The General Electric study found the general corrosion rates of SA533 Grade B carbon steel, Type 304 stainless steel, and Inconel 600 to be approximately one order of magnitude lower in the LOMI reagent than in the CAN-DECON reagent, and no IGA or increased

susceptibility to SCC was observed. PNL similarly found that both lightly and heavily sensitized Type 304 stainless steel and Inconel 600 specimens exhibited low general corrosion rates in the LOMI solution. The Inconel 600 specimens exhibited some shallow pitting after AP. AP/NP, and AP/NP;LOMI treatments, but the pits repassivated in subsequent post-filming. No IGA or increased susceptibility to SCC was observed under any of the test conditions for either alloy studied by PNL.

\section{Chemiral Cleaning of Steam Generators}

In the past nine years, the Electric Power Research Institute Steam Generators Owners Group has eveloped solutions for the chemical cleaning of the secondary side of PWR steam generators to remove $\mathrm{Fe}$ and $\mathrm{Cu}$ corrosion produce sludge deposits. Because of the large volume of material to be removed, the solutions tend to be more concentrated than those used for primary system decontaminations, and the formulations that have been developed for the $\mathrm{Fe}$ and $\mathrm{Cu}$ removal steps are somewhat different. ${ }^{26-28}$ The principal active ingredient in both cases is ammonium EDTA (ethylenediaminetetraacetic acid), which is present at a concentration of $10 \mathrm{wt}$. $\%$ in the Fe solvent and $5 \mathrm{wt}$. \% in the $\mathrm{Cu}$ solvent. The $\mathrm{Fe}$ solvent also contains 1 wt. \% hydrazine to reduct $\mathrm{Fe}^{3+}$ to $\mathrm{Fe}^{2+}$, which is more easily complexed by EDTA. The two solvents are typically used sequentially, with interspersed rinses, and the application temperatures are 88 to $96^{\circ} \mathrm{C}\left(190\right.$ to $205^{\circ} \mathrm{F}$ ) for the $\mathrm{Fe}$ solvent and 32 to $43^{\circ} \mathrm{C}\left(90\right.$ to $\left.110^{\circ} \mathrm{F}\right)$ for the $\mathrm{Cu}$ solvent. In addition, a stronger solvent containing $20 \mathrm{wt}$ \% ammonium EDTA has been developed for dissolving sludge from crevices.

These concentrated solutions tend to be more corrosive than the dilute solutions used in primary system decontamination, and a series of corrosion tests was carried out during their development. $26,29,30$ This series consisted inostly of general corrosion tests, but limited crevice, galvanic, pitting, and 
U-bend tests were also conducted. Essentially all of the alloys found in PV.? steam generators were tested; weldments and sensitized test specimens were included. Corrosion coupons were also included as a part of the Millstone 2 steam generator cleaning conducted in 1985.27 For the most part, the general corrosion rates of the carbon and low-alloy steels have typically been found to be less than $0.13 \mathrm{~mm}$ ( 5 mils) per application, and serious galvanic, crevice, or pitting effects were generally not observed. In view of the limited number of steam generator rleanings expected nve : $:=$ life of a PWR, these rates appear to ie acceptabia. i iowever, unacieprably high localized corrosion rates of carbon and low-alloy steels were observed in some sample weldments, particularly when galvanically coupled to Inconel 600 . This effect appears to be influenced most strongly by variations in solvent corrosion inhibitor and weld configuration. Additional site-specific weld region corrosion testing and qualification was recommended before using the chemical cleaning process at a specific plant.

\section{POSSIBLE INTERACTIONS BETWEEN DECONTAMINATION AND AGING}

The aging effects discussed above are produced by metallurgical changes that occur throughout the volume of the material, and one would not expect these bulk aging effects to be significantly influenced by decontamination. which is a surface process. However, the microstructural changes produced at the surface of a component by an aging process such as low-temperature sensitization may affect the response of that component to decontamination. Decontamination surface effects can, in turn, greatly influence subsequent corrosion and crack initiation and growth at the component surface. Thus, the principal interaction between decontamination and metallurgical aging is likely to be the effect of aging on decontamination response and the subsequent effect of any surface changes produced by decontamination on corrosion and crack initiation and growth.

An early concern with decontamination was that it might cause IGA and possibly an increased susceptibility to SCC, particularly in sensitized material. This concern has been shown to have some basis in fact for the CAN-DECON process under certain severe conditions, as discussed above. However, the follow-up tests performid by London Nuclear and others provide persuasive evidence that IGA and SCC would not be expected under normal decontamination conditions, and, in addition, the CAN-DECON reagents have been reformulated to further reduce the likelihood of such problems.

The relatively high general corrosion rates observed for carbon and low-alloy steels in the CAN-DECON LND $101 \mathrm{~A}$ reagent are also of concern. Corrosion rates approaching $0.2 \mathrm{~mm} /$ day have been observed. and repeated decontaminations, as during extended-life operation, could lead to corrosion wastages in excess of the corrosion allowances for some components. The presence of cracks through the weld-deposited alistenitic stainless steel cladding of the reactor pressure vessel would locally expose the underlying low-alloy steel to these solutions. Corrosion inhibitors have been found effective in reducing corrosion rates, but the sulfur compounds commonly 
found in these inhibitors may cause pitting in the austenitic stainless steels. In the case of the LOMl reagent, the general corrosion rates of the carbon and low-alloy steets are about an order of magnitude lower, but excessive corrosion may still occur in PWR decontaminations during the NP oxidizing pretreatment. For both BWR and PWR decontaminations, very little data are available on possible corrosion cffects on the high-strength $\mathrm{Ni}$-base alloys used for core structural applications.

The effects of decontamination on aged cast duplex stainless steels have not been evaluated experimentally. The concern here is that, under certain conditions, decontamination might produce microscopically sharp surface irregularities through such localized corrosion processes as IGA, galvanic corrosicn at the boundaries between the ferrite and austentite grains, or preferential attack of one of the two phases. These irregularities could, in turn, contribute to reduced impact strength by acting as stress risers. This problem would be aggravated under conditions of extended-life service, since repeated decontaminations would accentuate the surface irregularities and the duplex alloys would have more time to embrittle because of aging effects.

Finally, additional data are needed on the corrosive effects 6 . the more concentrated solutions used to clean the secondary sides of steam generators. The localized corrosion of carbon and low-alloy steel weldments has been discussed above, and the contribution of this wastage to the possible fatigue cracking of secondary feedwater lines owing to cyclic thermal stresses produced by stratified flows must be considered. 31 In addition, further studies are needed on possible IGA and SCC effects, particularly on alloys that have been sensitized by welding or long-term aging.

\section{SUMMARY}

In summary, the considerable body of data on and experience with the chemical decontamination of nuclear reactor primary systems indicate no severe materials corrosion problems. However, concerns remain in several areas, including (1) the high corrosion rates of carbon and low-alloy steels in the CAN-DECON and possibly in the LOMI NP processes, and the effects of corrosion inhibitors on the pitting of stainless steels; (2) the possible non-uniform corrosion of the cast duplex stainless steels that results in the introduction of microscopic surface features which may accentuate possible aging embrittlement in these materials; and (3) the very limited data available on the high-strength Ni-base alloys used for core structural applications and on materials subjected to long-term aging. Additional data are needed on possible locaiizea corrosion and SCC effects associated with the chemical cleaning of the secondary side of PWR steam generators, particularly on aged and sensitized steam-generator alloys and weldments. These concerns and data needs will be addressed in the experimental portion of the present program. 


\section{REFERENCES}

1. A. K. Banerjee, C. F. Bergeron, and W. B. Dodson, "An Approach to Nuclear Power Plant Life Extension," Nucl. Saf. 2 7 (1986), 385-390.

2. C. A. Negin, L. A. Goudarzi, L. U. Kenworthy, and M. E. Lapides, "Planning Study and Economic Feasibility for Extended Life Operation of Light Water Reactor Plants," Report TPS 78-788 (CONF-790923), Electric Power Research Institute (September 1979).

3. C. A. Negin, R. S. Walker, and S. B. Shantzis, "Extended Life Operation of Light Water Reactors: Economic and Technological Review," EPRI NP-2418. Electric Power Research Institute (June 1982).

4. Northern States Power Company, "BWR Pilot Plant Life Extension Study at the Monticello Plant: Phase 1," EPRI NP-5181M, Electric Power Research Institute (May 1987).

5. R. B. Minogue, "Trends in Nuclear Safety Research--Looking Ahead to the 1990's," Proc. Thirteenth Water Reactor Safety Research Information Meeting," NUREG/CP-0072, Vol. 1 (February 1986), pp. 1-8.

6. U. S. Nuclear Regulatory Commission, "Nuclear Plant Aging Research (NPAR) Program Plan," NUREG-1 144 (July i985).

7. M. J. Povich, "Low Tenuerature Sensitiztion of Type 304 Stainiess Steel," Corrosion $\underline{34}$ (1978), 60-65.

8. M. J. Povich and P. Rao, "Low Temperature Sensitiztion of Welded Type 304 Stainless Steel," Corrosion $\underline{34}$ (1978), 269-275.

9. O. K. Chopra and H. M. Chung, "Aging Degradation of Cast Stainless Steel," Proc. Fourteenth Water Reactor Safety Research Information Meeting." NUREG/CP-0082, Vol. 2 (February 1987), pp. 119-142.

10. R. A. Shaw, "Getting at the Source: Reducing Radiation Fields," Nucl. Technol. 44 , (1979), 97.

11. J. E. LeSurf and G. D. Weyamn, "Cost-effectiveness of Dilute Chemical Decontarnination:" Proc. 1981 ANS Winter Mtg., San Francisco, CA, Nov. 29-Dec. 3, 1981; Trans. Am. Nucl. Soc. $\underline{39}$ (1981), 865.

12. C. J. Wood, "Decontamination Helps Control Nuclear-maintenance Costs," Poiver 129 (January 1985), 29-33. 
13. R. Knox, "How Independent Tests Have Eliminated Can-Decon Corrcsion Concerns," Nucl. Eng. Int. $\underline{32}$ (March 1987), 48-51.

14. J. F. Remark, "Plant Decontamination Methods Review," EPRI NP-1 168 , Electric Power Research Institute (March 1981).

15. J. L. Smee, "Decontaminating LWRs with Can-Decon Dilute Processes," Nucl. Eng. Int. $\underline{30}$ (January 1985), 29-33.

16. J. P. Michalko, P. J. Bonnici, and J. L. Smee, "Compilation of Corrosion Data on CAN-DECON ${ }^{\mathrm{TM}}$. Volume 1: General, Galvanic, Crevice, and Pitting Corrosion Data from CANDU and BWR Tests," EPRI NP-4222, Vol. 1. Electric Power Research Institute (October 1985).

17. Anon., "Decon Cracking Fears are Allayed," Nucl. Eng. Int. 29 (October 1984), 11.

18. Anon., "Does Can-Decon Encourage Pipe Cracking?," Nucl. Eng. Int. $\underline{30}$ (February 1985), 13.

19. M. T. Wang, "Corrosion Evaluation of Two Processes for Chemical Decontamination of BWR Structural Materials," EPRI NP-4356, Electric Power Research Institute (December 1985).

20. J. P. Michalko and J. L. Smee, "Compilation of Corrosion Data on CAN-DECON'M, Volume 2: Influence of CAN-DECON orı Stress Corrosion Cracking--Summary of Tesuing, 1975-1983," EPRI NP-4222, Vol. 2, Electric Power Research Institute (October 1985).

21. P. J. King and B. D. Warr, "Compilation of Corrosion Data on CAN-DECONTM, Volume 3: Influence of CAN-DECON Process on Stress Corrosion Cracking--1984 Constant-Extension-Rate Tests," EPRI NP-4222, Vol. 3, Electric Power Research Institute (January 1987).

22. J. L. Smee and V. C. Turner, "Compilation of Corrosion Data on CAN-DECON ${ }^{\top M}$, Volume 4: General, Galvanic, Crevice, Pitting, and Stress Corrosion Data From PWR Tests and Applications," EPRI NP-4222, Vol. 4, Electric Power Research Institute (January 1987).

23. J. L. Smee and V. C. Turner, "Compilation of Corrosion Data on CAN-DECONTM, Volume 5: Influence of the CAN-DECON ${ }^{\mathrm{TM}}$ Process on Stress Corrosion Crackirig--Summary of Testing 1984-1985," EPRI NP-4222, Vol. 5. Electric Power Research Institute (January 1987). 
24. A. Cruickshank, "Deveioping Techniques for Decontamination," Nucl. Eng. Int. 28 (November 1983), 41-44.

25. R. L. Clark and R. L. McDowell, "Corrosion Testing of LOMI Decontamination Reagents," EPRI NP-3940. Electric Power Research Institute (March 1985).

26 P. C. Hildebrandt, J. E. Nestell, R. C. Trench, and R. D. Vurin, "weld Region Corrosion During Chemical Cleaning of PWR Steam Generators, Vol. 1: Overview and Discussion," EPRI NP-5267, Vol. 1, Electric Power Research Institute (July 1987).

27. N. R. Stolzenterg and R. C. Thomas, "Employing a Chemical Method for Tubesheet Sludge Removal," Nucl Eng. Int. 32 (January 1987), 39-41.

28. Anon.., "Removing Magnetite from the Oconee Steam Generators," Nucl. Eng. Int. 32 (March 1987), 51-52.

29. E. L. Capener, G. R. Egan, and T. J. Feiersen, "PWR Steam Generator Chemical-Cleaning Data Base," EPRI NP-3477, Vols 1 \& 2, Electric Power Research Institute (April 1984).

30. J. L. Barna et al., "Weld Region Corrosion During Chemical Cleaning of PWR Steam Generators, Vol. 2: Tests and Analyses," EPRI NP-5267, Vol. 2, Electric Power Research Institute ('Tuly 1987).

31. Investigation and Evaluation of Cracking Incidents in Piping in Pressurized Water Reactors, Report of the USNRC PWR Pipe Crack Study Group, NUREG-0691 (September 1980). 